\title{
Performance Comparison based on Open Shortest Path First (OSPF) Routing Algorithm for IP Internet Networks
}

\author{
Ida Nurhaida \\ Universitas Mercu Buana \\ Jalan Raya Meruya Selatan no. 1, \\ Kebon Jeruk \\ West Jakarta, 11650
}

\author{
Desi Ramayanti \\ Universitas Mercu Buana \\ Jalan Raya Meruya Selatan no. 1, \\ Kebon Jeruk \\ West Jakarta, 11650
}

\author{
Imay Nur Islamiyah \\ Departement of NOC, ATS, Internet \\ Service Provider \\ West Jakarta-11750, Indonesia
}

\begin{abstract}
Due to the rapid development of technology, the higher demands of internet network users who want a form of network that can provide maximum results are increasing. In this case, Routing is one of the critical components of the network infrastructure on the Internet today, but routing performance on the router will increasingly burden the performance of the router. Consequently, it needs the addition of network scenario or management for backbone that has been built. In this case, the performance is compared to the addition of VLAN management scenarios on OSPF and combination of OSPF with VPLS Management over MPLS. The VLAN management on OSPF has the best performance, which gets throughput value up to $59.6 \%$, packet loss up to $0.32 \%$, jitter and delays $4.44 \mathrm{~ms}$ respectively.
\end{abstract}

\section{General Terms}

Network Computing, Routing Protocol

\section{Keywords}

OSPF, VLAN, VPLS over MPLS, QoS

\section{INTRODUCTION}

The development of computer technology is increasing along with the development of human's needs in getting information using the internet. With the various needs available on the internet, internet connection has been becoming an essential component. Nowadays, information technology is the need for business and other activities. So the purpose of the computer network is to bring information precisely without any mistakes from the transmitter to a receiver through communication media [1]. The number of internet users in Indonesia has increased every year. It is proved by the data presented from the Indonesian Internet Service Providers Association (APJII), as shown in Fig. 1 [2]. The data describes the use of internet technology in Indonesia has been growing since 1998. Initially, the internet users in Indonesia were only 0.5 million people. It grew up to 143.26 million people in 2017. Then, it gradually increases in the following year [2]. Due to the increasing needs of a computer network, so network management has to operate and maintain the communication network [3]. Network operators must implement low-level vendor-specific configuration to apply a policy of the high-level system [4]. In this case, Routing is the main components of the infrastructure

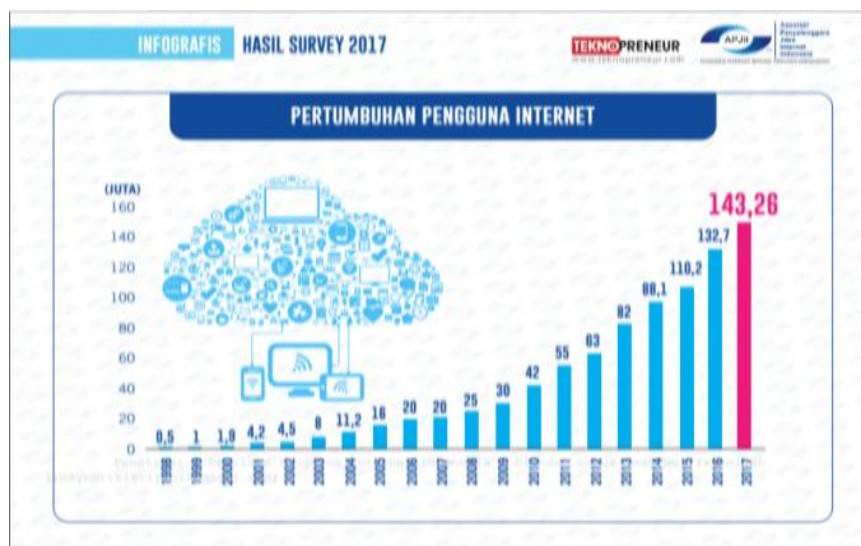

Fig 1: The use of internet in Indonesia

network on the internet [5]. A routing protocol is used by the router to make network mapping, so the router can decide how to forward packets from a point to another. Two classes of the routing protocol used on the internet are distance vector and link-state [6]. Routing Algorithm determines the lowest cost between two nodes. Rathi et al. analyse the performance of the routing protocol using a distance-vector that is the Routing Information Protocol (RIP). The Bellman-Ford algorithm is applied to find the shortest paths shipping [7]. Meanwhile, Open Shortest Path First (OSPF) is a protocol based on Dijkstra's algorithm to select the best route. OSPF is a routing protocol which implemented the Interior Gateway Protocol (IGP) that can only work in an internal network of an organisation or a company [8].

The using of the redundant router in a medium to the extensive network will increase the packet delay and will reduce the efficiency of network communication as well. Consequently, it can cause some effects such as decreased speed and bottleneck in the network [9]. As a result, a technology that mixes routing with switching has emerged to solve those problems [10]. In this research, the combination of layer 2 and layer 3 is examined using the design of linkstate routing protocol OSPF based on Dijkstra's algorithm. Layer 2 is including a virtual local area network (VLAN) and virtual private LAN service (VPLS). The implementation of the network will need multi-protocol label switching (MPLS) from the layer 2.5 .

The underlying reason that makes the router cannot be used to divide the broadcast domain like a switch is that the router needs more time to process the incoming data (Cisco, 2016) [11]. VLAN can reduce congestion in the big LAN. It can break big physical LAN becoming small logical LAN to overcome high traffic. It can classify hosts, although the hosts 
are not in the same physical segment [12]. Meanwhile, this MPLS use labelling packet as the basics of ATM technology. However, because of the flexibility and scalability, MPLS technology is reliable and easy to implement. There are many services and protocols such as IP routing, and VPN can work on it. MPLS provides L2TP in Virtual Private LAN Service (VPLS) that is a technology multipoint-to-multipoint tunnelling in layer 2 [13].

The paper is organised as follows. In Section 2, the underlying theoretical, algorithm, and previous researches are elaborated. In Section 3, we are explaining the research methodology, design and analysis are including the layout of routing OSPF (layer 3), Quality of Services (QoS) and VLAN management. Finally, the result of the experiments in Section 4 and conclusions are given in Section 5.

\section{LITERATURE REVIEW}

\subsection{Router}

A router is a network device used to forward data packets through a network [14]. Routing process occurs in Layer 3 OSI called Network Layer. The router will distribute data packets to two or more networks in the same or different segments [15].

\subsection{Dijkstra's Routing Algorithm}

Routing protocol builds a routing table according to routing algorithm processes. Routing protocol arranges working process and working characteristic from a routing protocol [15]. Based on the routing algorithm, the routing protocol is divided into two big categories, including distance vector routing protocol (Bellman-ford Algorithm) and link-state routing protocol (Dijkstra's Algorithm). The problem occurs when a network administrator has to decide the shortest path from a network topology [16]. Dijkstra's Algorithm, was conceived by Edsger Dijkstra, is an algorithm with the greedy principal that solves the problem of the shortest path for a direct graf with non-negative weights [17]. The following is pseudocode Dijkstra's algorithm:

\section{Dijkstra's procedure}

(

input m: matriks, a: integer \{first node\}

)

Lfind shortest line from first node a to all nodes Input: neighbour matrices $(m)$ from a weighted graph $G$ and first node an Output: shortest line from a to all nodes

\section{DICTIONARY}

$s 1, s 2, \ldots, s n:$ interger $\{$ interger line\}

$d 1, d 2, \ldots, d n:$ interger $\{$ interger line \}

$i:$ integer

ALGORITHM

\{Step O (Initialization) : \}

for $i \leftarrow 1$ to $n$ do

si $\leftarrow 0$

di $\leftarrow m a i$ endfor

\{Step 1: \}

$s a \leftarrow 1$

\{because node a is the shortest sources line, so it is choosen in shortest line\}

da $\leftarrow$ infinity

\{no shortest line from node a to a \}

Step $2,3, \ldots, n 1:\}$

for $i \leftarrow 2$ to $n-1$ do

$\{$ Find $j$ so that $s j=0$ and $d j=\min (d 1, d 2, \ldots, d n)\}$

Sj $\leftarrow 1$

\{node $j$ was chosen in the shortest line\}

$\{$ renew di, for $I=1,2,3, \ldots, n$ with $:$ di $($ new $)=\min \{d i($ old $), d j+$ mii\}

endfor [18].

\subsection{Virtual Local Area Network (VLAN)}

According to Stephen McQuerry et al., VLAN is a broadcast domain in the switch to activate control of broadcast, multicast, unicast, and unknown unicast in layer 2. The VLAN purpose to enhance the network performance by dividing the larger broadcast domain to some smaller broadcast domains [12]. Communication between VLAN needs routing. Consequently, it is required VLAN Management in the path because of its independent logic network segment and broadcast domain in each VLAN only limited to internal VLAN. Through an external router, communication between VLAN can be conducted merely. Router plays a role to forward routing, firewall, and broadcast segregation. People must use one router for one path in each packet [19].

\subsection{MPLS}

Multiprotocol Label Switching (MPLS) is a technology of packet-carrying used in the service provider and company network. MPLS uses a label to make a forwarding decision compared to the traditional IP network approach. A router directs some routing protocols and makes an independent forwarding decision based on the IP packet header. Every router analysis header that can be seen in its routing table and chooses the next right hop router. This searching process must be conducted independently every time in every single IP packet because the content of the routing table can be changed once in a while [20]. By using MPLS, when a packet enters form IP network to MPLS network for the first time, it is assigned to the Forwarding Equivalence Class (FEC). The router adds a label to that packet. FEC. That treatment based on the IP address, port information, DSCP, etc. Each router knows how to direct a packet with specific FEC. After the packet had arrived in the MPLS network, it will not need to analyse the header again [21].

\subsection{VPLS}

Virtual Private LAN Service (VPLS) is multifunction VPN to multipoint Layer 2 from Ethernet-based. VPLS overcomes the limitation of other Layer 2 VPN by serving style service "switch in the cloud". VPLS enables the connection from the client to the geographic sites. It is similar to the connection between the remote location in the same LAN [21]. Fig. 2 
describe MTU consideration on VLAN, MPLS, and VPLS.

\subsection{Quality of Service (QoS)}

Flannagan et al. (2003) define that QoS is a technique to manage bandwidth, throughput, delay, jitter, and packet loss for wires in the network. The purpose of the QoS mechanism is to affect at least one of four QoS necessary parameters that have been decided. QoS is designed to help end-user to be more productive by ensuring that the user gets excellent performance from applications. QoS refers to the ability of the network to

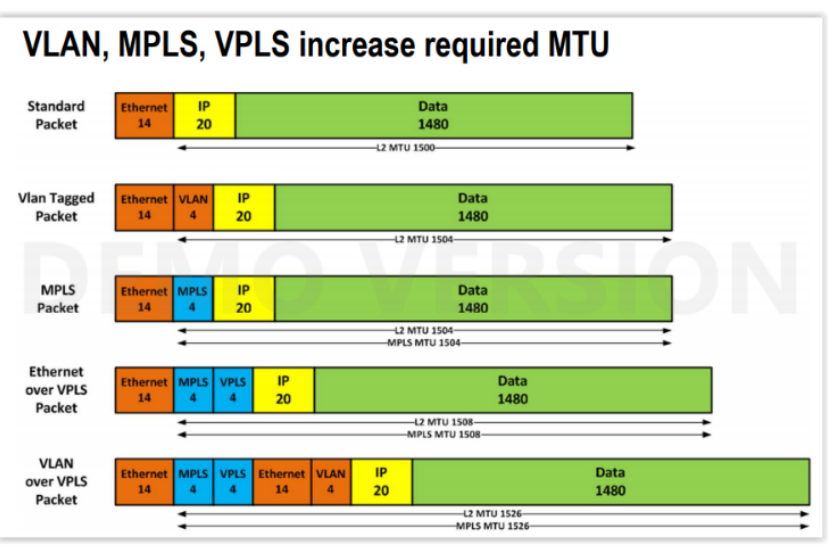

Fig 2: MTU Consideration

provide better services on specific network traffic through different technology. QoS is a big challenge in a network with an IP basis and internet virtually [22]. The purpose of QoS is to fulfil the needs of different service that use the same infrastructure. QoS offers the ability to define services attributes qualitatively as well as quantitatively [23].

Table 1. QoS Parameter Indexs [24]

\begin{tabular}{|c|c|c|}
\hline Values & Percentage (\%) & Indexs \\
\hline $3,8-4$ & $95-100$ & Very good \\
\hline $3-3,79$ & $75-94,75$ & Good \\
\hline $2-2,99$ & $50-74,75$ & Moderate \\
\hline $1-1,99$ & $25-49,75$ & Bad \\
\hline
\end{tabular}

\subsubsection{Throughput}

Throughput is the rate of the successful delivery message which measured in bps (bit per second). Throughput is the total sum of the success arrived packet observed in the object during the specific time interval divided by that time interval duration. The Throughput category is presented in Table 2 [24].

Table 2. Throughput Category [24]

\begin{tabular}{|l|l|l|}
\hline Throughput Category & Throughput (\%) & Indexs \\
\hline Very Good & $76-100$ & 4 \\
\hline Good & $51-75$ & 3 \\
\hline Moderate & $26-50$ & 2 \\
\hline Bad & $<25$ & 1 \\
\hline
\end{tabular}

The formulation of Throughput:

$$
\text { Throughput }=\frac{\text { The accepted data packets }}{\text { The duration of observation }}
$$

\subsubsection{Packet Loss}

Packet Loss is a parameter that drawn a condition in which the sum of total packet loss occurs because of collision and congestion in the network. Index and packet loss category are shown in Table.3 [24].

Table 3. Packet Loss Category [24]

\begin{tabular}{|c|c|c|}
\hline $\begin{array}{c}\text { Degradatio } \\
\text { n Category }\end{array}$ & Packet Loss $(\boldsymbol{\%})$ & Index \\
\hline Very Good & 0 & 4 \\
\hline Good & 3 & 3 \\
\hline Moderate & 15 & 2 \\
\hline Bad & 25 & 1 \\
\hline
\end{tabular}

The equation of Packet Loss:

$$
\begin{aligned}
& \text { Packet loss: } \\
& =\frac{(\text { Delivered data packet }- \text { Accepted packet })}{\text { Delivered data packet }} \times 100 \%
\end{aligned}
$$

\subsubsection{Delay}

Delay is the time required for a packet to go through the distance from the origin to destination. Delay can be affected by distance, physical media, congestion or extended processing time. Delay category is presented in Table.4 [24].

Table 4. Delay Category [24]

\begin{tabular}{|l|c|l|}
\hline Latency Category & Delay $(\mathrm{ms})$ & Indexs \\
\hline Very good & $0 \mathrm{~ms}$ & 4 \\
\hline Good & $0 \mathrm{~ms} \mathrm{~s} / \mathrm{d} 75 \mathrm{~ms}$ & 3 \\
\hline Moderate & $75 \mathrm{~ms} \mathrm{~s} / \mathrm{d} 125 \mathrm{~ms}$ & 2 \\
\hline Bad & $>125$ & 1 \\
\hline
\end{tabular}

The formulation of Delay:

\subsubsection{Jitter}

$$
\text { Delay }=\frac{\text { Total of the Delay }}{\text { Total sum of packet }}
$$

Jitter is affected by delay variations during processing time and packet re-gathering time in the last jitter trip. Jitter generally called a delay variation which has a close relation with latency that shows many delay variations in data transmission in the network. It can be seen in Table. 5 [24].

Table 5. Jitter Category [24]

\begin{tabular}{|l|c|l|}
\hline Jitter Category & Jitter (ms) & Index \\
\hline Very Good & $0 \mathrm{~ms}$ & 4 \\
\hline Good & $0 \mathrm{~ms} \mathrm{~s} / \mathrm{d} 75 \mathrm{~ms}$ & 3 \\
\hline Moderate & $75 \mathrm{~ms} \mathrm{~s} / \mathrm{d} 125 \mathrm{~ms}$ & 2 \\
\hline Bad & $>125$ & 1 \\
\hline
\end{tabular}

The equation of Jitter:

$$
\text { Jitter }=\frac{\text { Total of Delay Variation }}{\text { Total of accepted packet }}
$$


The Total of Delay Variation = Delay $-($ delay average $)$

\section{Research Methodology}

This research is using the Network Development Life Cycle

(NDLC) is a method that depends on the previous building

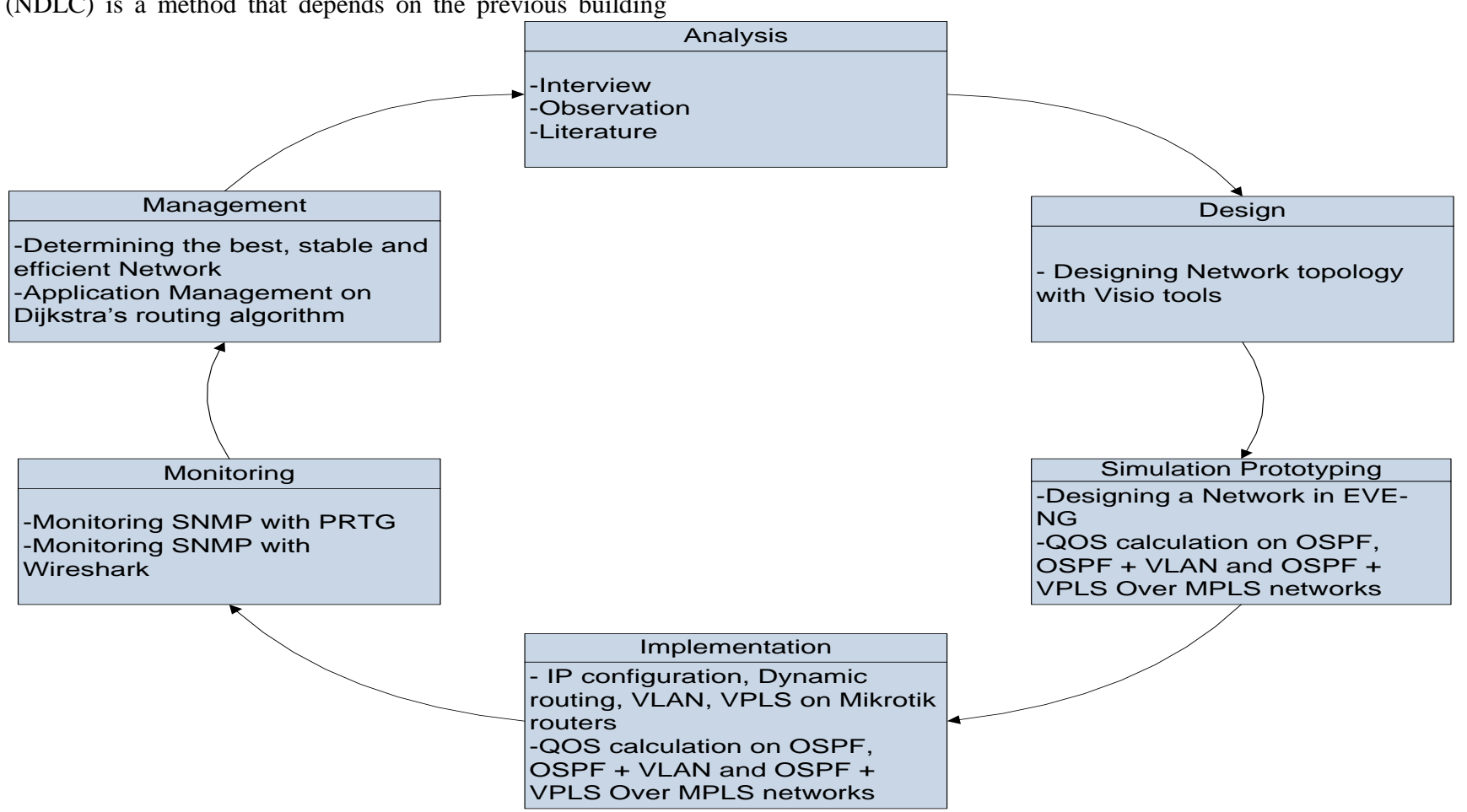

Fig 3: NDLC Research Cycle

\subsection{Analysis}

In this stage, the experiments are conducted based on requirement analysis, emerging problem, and user's requirement as follows:

1. Interview with concerned parties, including customers and company management, to get concise and complete data.

2. Observation directly to get the real phenomenon.

3. Literature review including theories, findings and previous researches, which are used as the underlying theory for this research

\subsection{Simulation / Prototype}

In this stage, several tools are used for simulation as follow:

1. Plan network in simulation environment EVE-NG and VMware Workstation

2. QoS measure using Wireshark as a tool for network performance.

\subsection{Implementation}

The configurations of the Mikrotik router are implemented as follows:

1. Configure dynamic routing with OSPF using Dijkstra's algorithm.

2. Measure QoS in the planning of dynamic routing OSPF [26].

3. Configure Virtual Local Area Network process such as business strategy planning, application development life cycle, and analysis of data distribution [25]. The following is the stages of NDLC as shown in Fig. 3.
Management (VLAN)

4. Configure the mixing of layer 3 and layer 2

5. Measure QoS after improving VLAN Management in dynamic routing OSPF [26].

6. Configure cloud VPLS over MPLS

7. Configure the mixing of layer 3 and layer 2 as well as layer 2.5

8. Measure QoS after improving cloud VPLS over MPLS [26].

\subsection{Monitoring}

Bandwidth traffic and CPU load are using PRTG monitoring system to ensure that the network can work based on the purpose of this research.

\subsection{Management}

Management takes a specific interest in the policy. The policy must be made to create or set the built system. The procedure depends on the management level policy and business strategy of the company.

\subsection{Design}

The network topology, access data design, and wires layout design will be seen in Fig. 4.

\subsection{Design OSPF Routing}

To build a routing network, the devices that must be used are: 
1. Mikrotik Router

- Core Router

- OSPF Router
2. Windows $\mathrm{PC}$ for client

The picture of the OSPF routing topology will be built, as shown in Fig. 5.

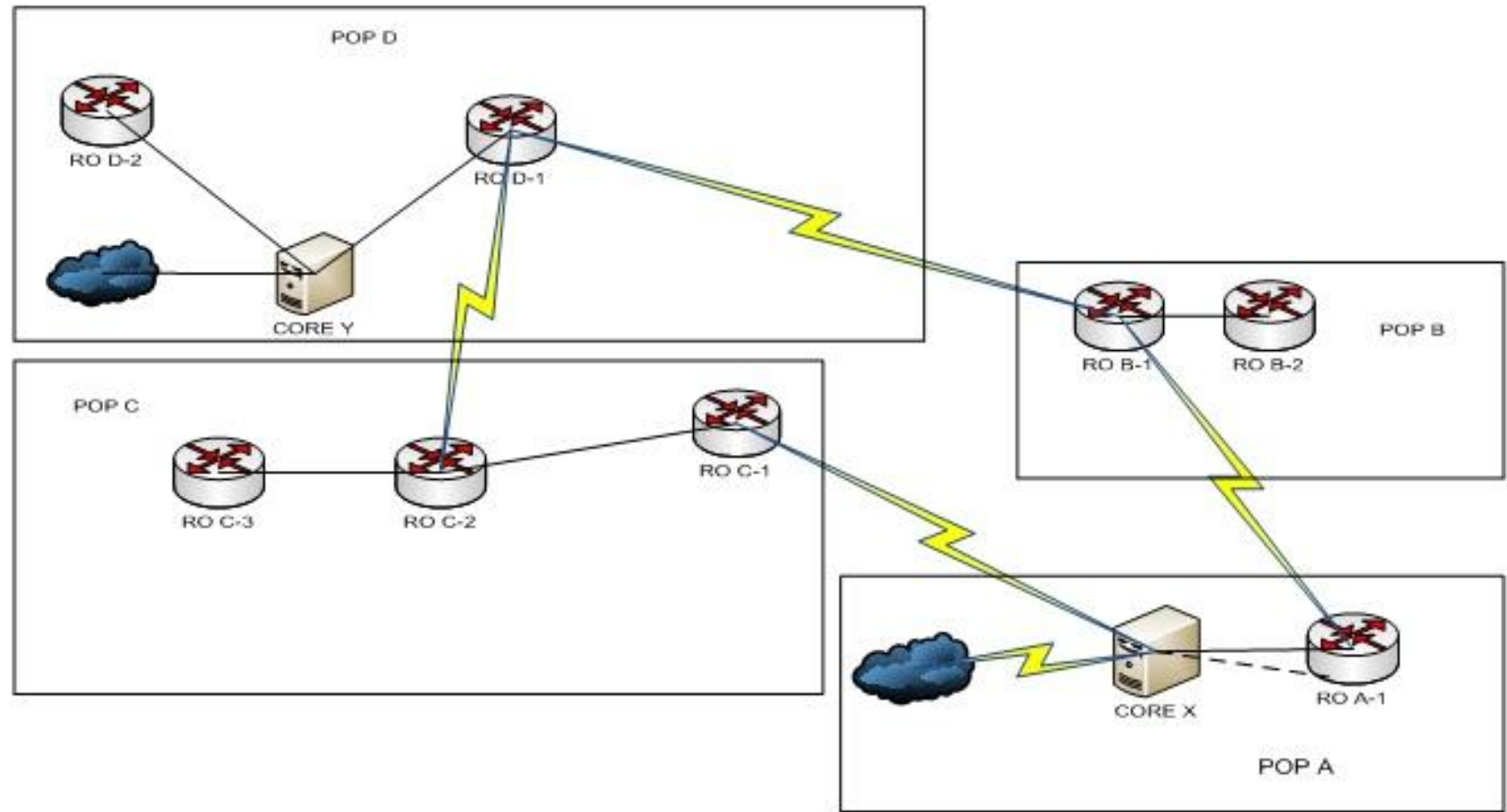

Fig 4: Network Topology Design

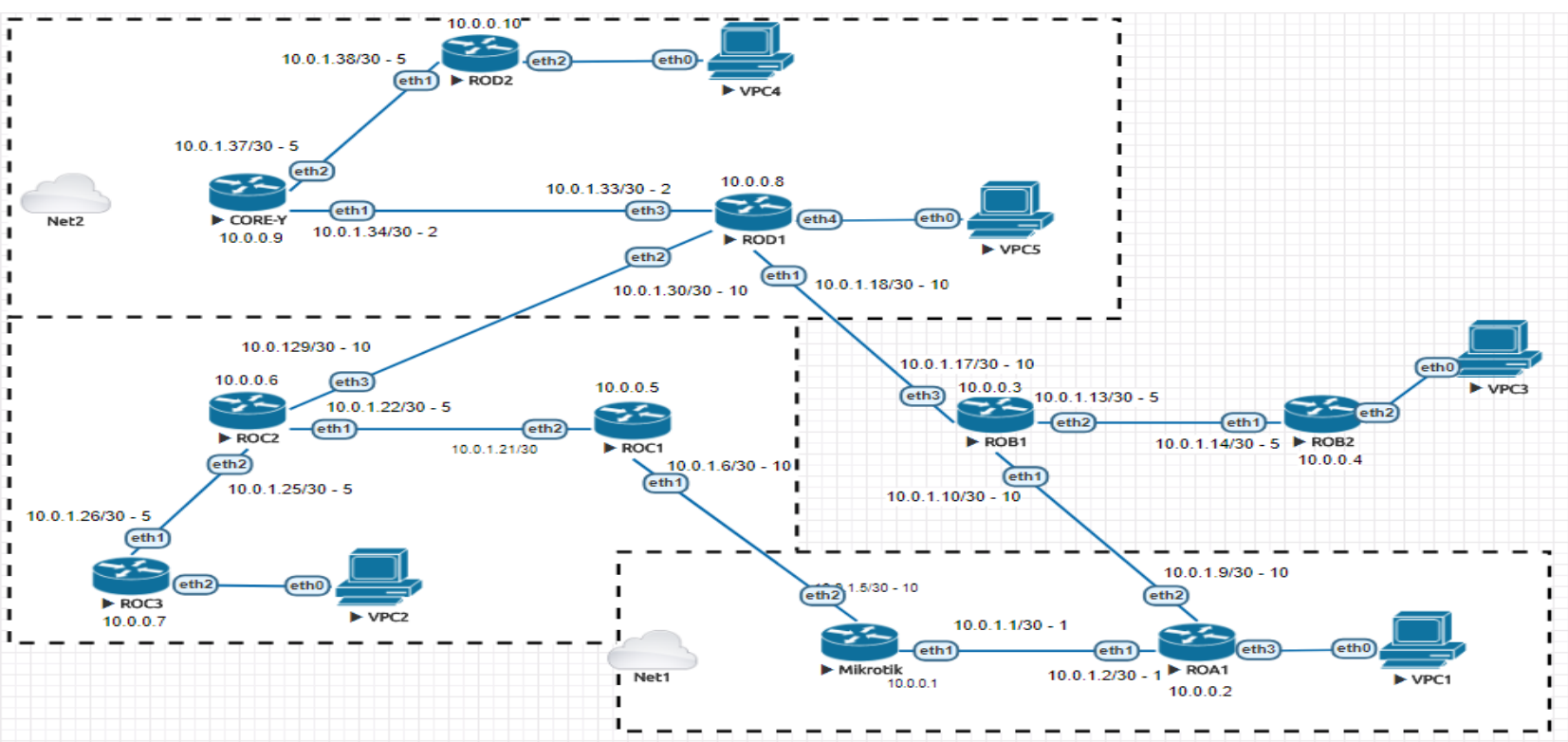

Fig 5: Routing OSPF Topology

Configuration of IP and OSPF Routing on Core-X:

lip address

add address $=10.0 .0 .1 \quad$ interface $=$ bridge-loopback add address $=59.153 .82 .10 / 30$ comment $=$ WAN interface $=$ ether 1 ATS network $=59.153 .82 .8$

add address=10.0.1.1/30 interface $=$ ether 2 -CoreX-to-ROA12011 network $=10.0 .1 .0$

/routing ospf instance set [ find default=yes ] distribute-default=if-installed-as-type1 redistribute-connected $=$ as-type-1 router-id=10.0.0.1

/routing ospf interface

add authentication=md5 authentication-key=@Admin $1-2$ cost $=1 \quad$ interface $=$ ether 2 -CoreX-to-ROA1-2011 networktype $=$ point-to-point

Irouting ospf network

add area $=$ backbone network=10.0.1.0/30 
Configuration of IP and OSPF Routing on ROD1:

/ip address

add address $=10.0 .0 .8 / 32 \quad$ interface $=$ bridge-loopback network $=10.0 .0 .8$

add address $=10 \cdot 0 \cdot 1 \cdot 18 / 30$ interface $=$ ether $1-R O D 1-$ to-ROB1 network $=10.0 .1 \cdot 16$

add address $=10.0 .1 .33 / 30 \quad$ interface $=$ ether $2-R O D 1-$ to COREY

network $=10 \cdot 0 \cdot 1.32$

add address $=172 \cdot 18 \cdot 17 \cdot 1 / 24$ interface $=$ ether $3-L A N$

network=172.18.17.0

/routing ospf area

add area-id=0.0.0.1 name $=$ areal

/routing ospf instance

set [ find default=yes ] redistribute-connected=as-type-1

router-id=10.0.0.8

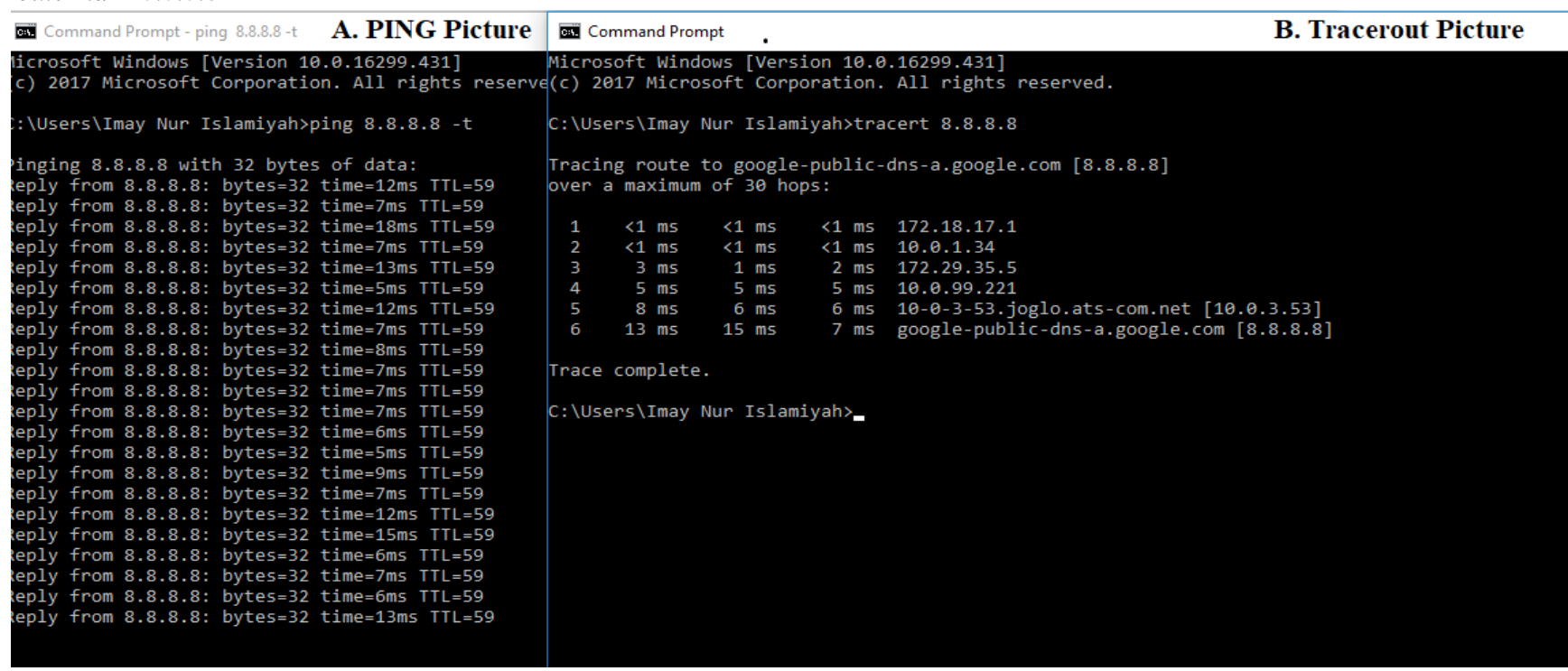

Fig 6: Ping and Traceroute via link primary

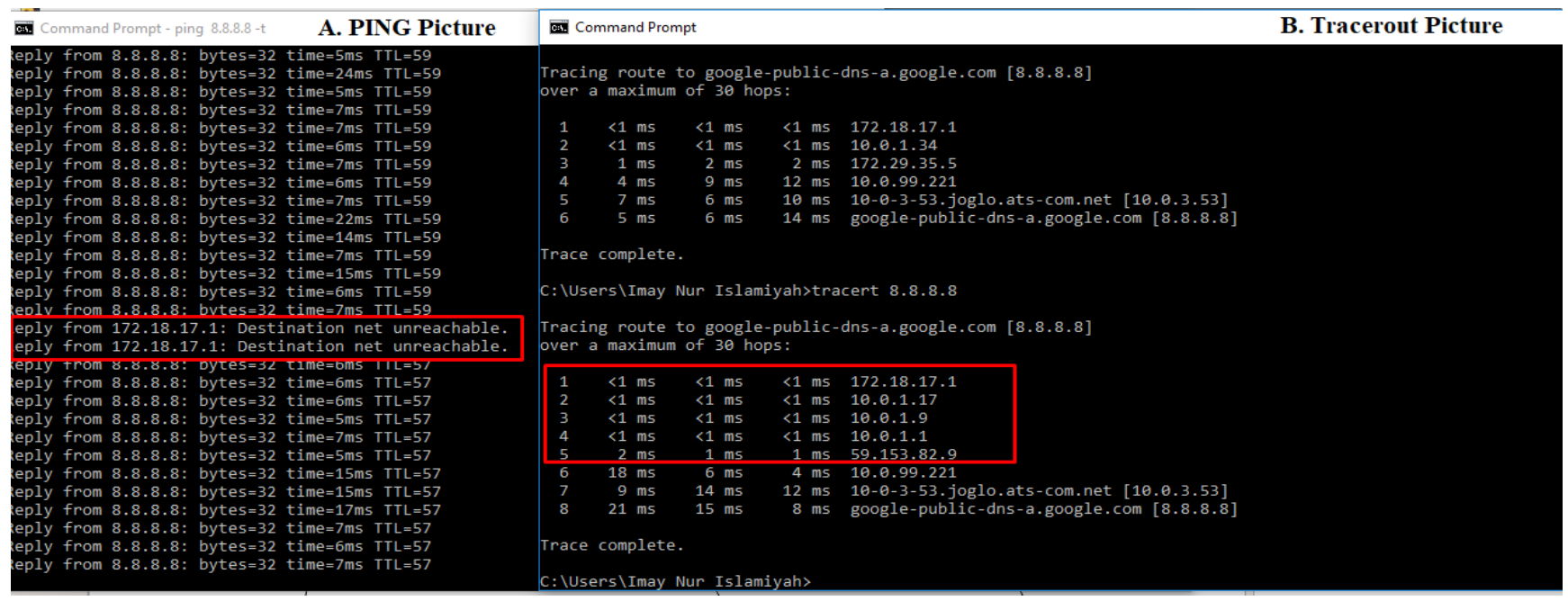

Fig 7: Ping and Taceroute via link backup 


\section{DESIGN AND IMPLEMENTATION}

\subsection{OSPF Routing Design using VLAN Management}

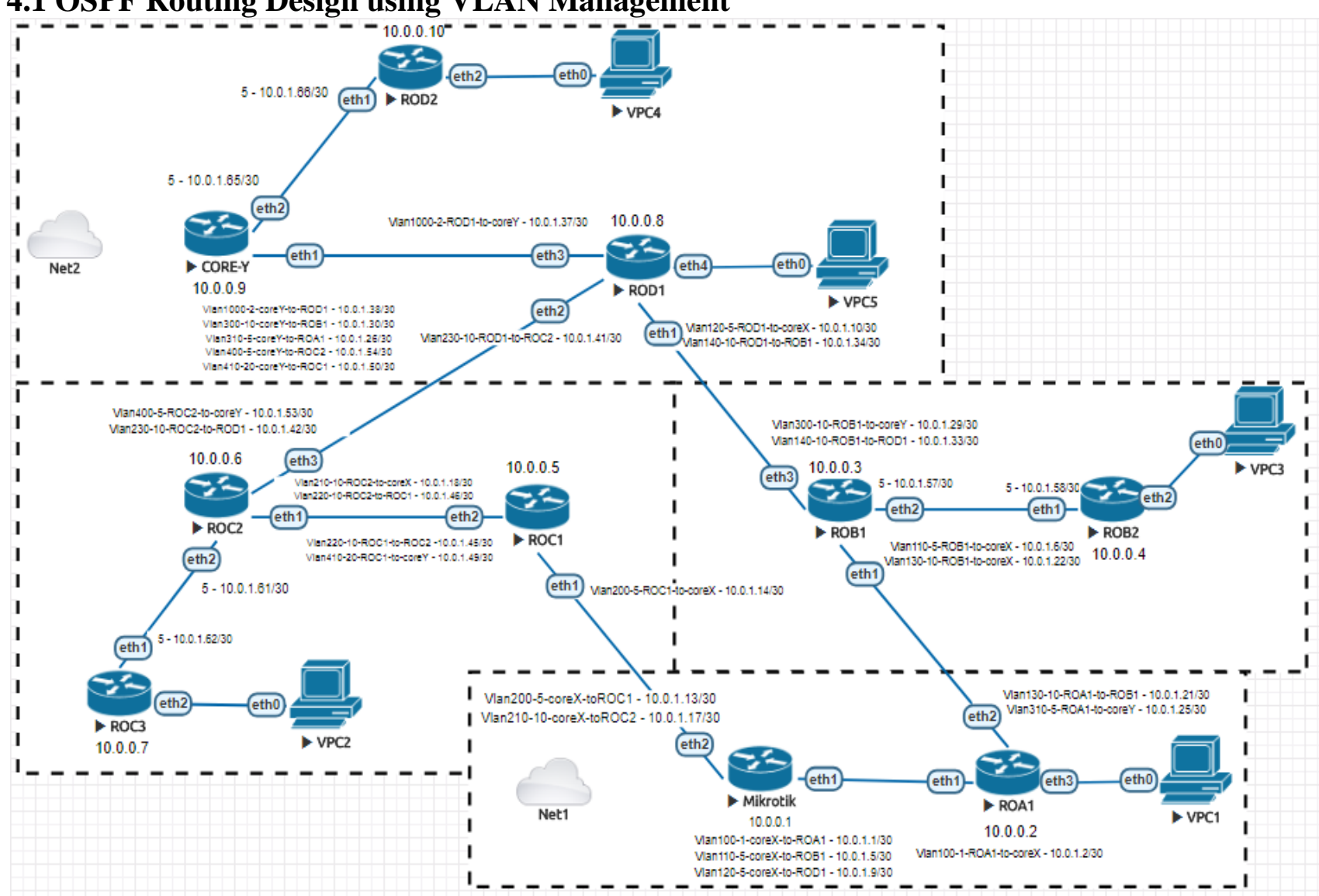

The extended topology OSPF using VLAN management is presented in Figure 8. This topology was built based on Figure 7.

Fig 8: VLAN Management Topology in OSPF Routing

Configuration of IP and Routing OSPF + VLAN on Core-X:

/ip address

add address $=$ 10.0.0.1 interface $=$ bridge - loopback network $=10.0 .0 .1$

add address $=59.153 .82 .10 / 30 \quad$ comment $=$ WAN interface $=$ ether 1 -ATS network $=59.153 .82 .8$

add address $=10 \cdot 0.1 \cdot 1 / 30 \quad$ interface $=$ Vlan100-1-coreX-toROA1 network $=10.0 .1 .0$

add address $=10.0 .1 .5 / 30 \quad$ interface $=$ Vlan110-5-coreX-toROB1 network=10.0.1.4

add address $=10.0 .1 .9 / 30 \quad$ interface $=$ Vlan120-5-coreX-toROD1 network=10.0.1.8

/routing ospf instance

set [ find default=yes ] distribute-default=if-installed-as-type1

redistribute-connected $=$ as - type -1 router - id $=10.0 .0 .1$

/routing ospf interface

add authentication $=m d 5$ authentication $-k e y=$ Vlan100 cost $=1$ interface $=$ Vlan100-1-coreX-to-ROA1 network-type $=$ point-topoint

add authentication $=m d 5$ authentication - key $=$ Vlan110 cost $=5$ interface $=$ Vlan1 10-5-coreX-to-ROB1 network-type $=$ point - to point

add authentication $=m d 5 \quad$ authentication - key $=$ Vlan 120 cost $=120$ interface $=$ Vlan120-5-coreX-to-ROD1 networktype $=$ point-to-point

add authentication $=m d 5$ authentication $-k e y=V p s 100$ cost $=1$

disabled $=y e s$ interface $=v p l s$-to-roal network-type $=$ point - to point

Irouting ospf network

add area $=$ backbone network $=10 \cdot 0 \cdot 1 \cdot 0 / 30$

add area $=$ backbone network $=10 \cdot 0 \cdot 1 \cdot 4 / 30$

add area $=$ backbone network $=10 \cdot 0 \cdot 1 \cdot 8 / 30$

Configuration of IP and Routing + VLAN on ROD1:

/ip address

add address $=10.0 .0 .8 / 32 \quad$ interface $=$ bridge-loopback network $=10.0 .0 .8$

add address $=172.18 .17 .1 / 24 \quad$ interface $=$ ether $3-L A N$ network $=172.18 .17 .0$

add address $=10 \cdot 0 \cdot 1 \cdot 10 / 30 \quad$ interface $=$ Vlan120-5-ROD1-tocoreX network $=10.0 .1 .8$ 
add address $=10 \cdot 0 \cdot 1.34 / 30$ interface $=$ Vlan140-10-ROD1-toROB1 network $=10.0 .1 .32$

add address $=10 \cdot 0 \cdot 1.37 / 30$ interface $=$ Vlan1000-2-ROD1-tocoreY network=10.0.1.36

/routing ospf area

add area-id=0.0.0.1 name $=$ areal

Irouting ospf instance

set [ find default=yes ] redistribute-connected=as-type-1 router-id $=10 \cdot 0.0 .8$

/routing ospf interface

add authentication $=m d 5$ authentication $-k e y=$ Vlan 120 cost $t=5$ interface $=$ Vlan120-5-ROD1-to-coreX network-type $=$ point-topoint add authentication $=m d 5 \quad$ authentication $-k e y=$ Vlan 140 interface $=$ Vlan140-10-ROD1-to-ROB1 network-type $=$ point to-point

add authentication $=m d 5 \quad$ authentication - key $=$ Vlan 1000 cost $=200$ interface $=$ Vlan1000-2-ROD1-to-coreY networktype $=$ point-to-point

/routing ospf network

add area=backbone network=10.0.1.32/30

add area $=$ backbone network=10.0.1.36/30

add area $=$ backbone network=10.0.1.8/30

Figure 9 presents the resulting ping and traceroute based on OSPF with VLAN management from PC5.

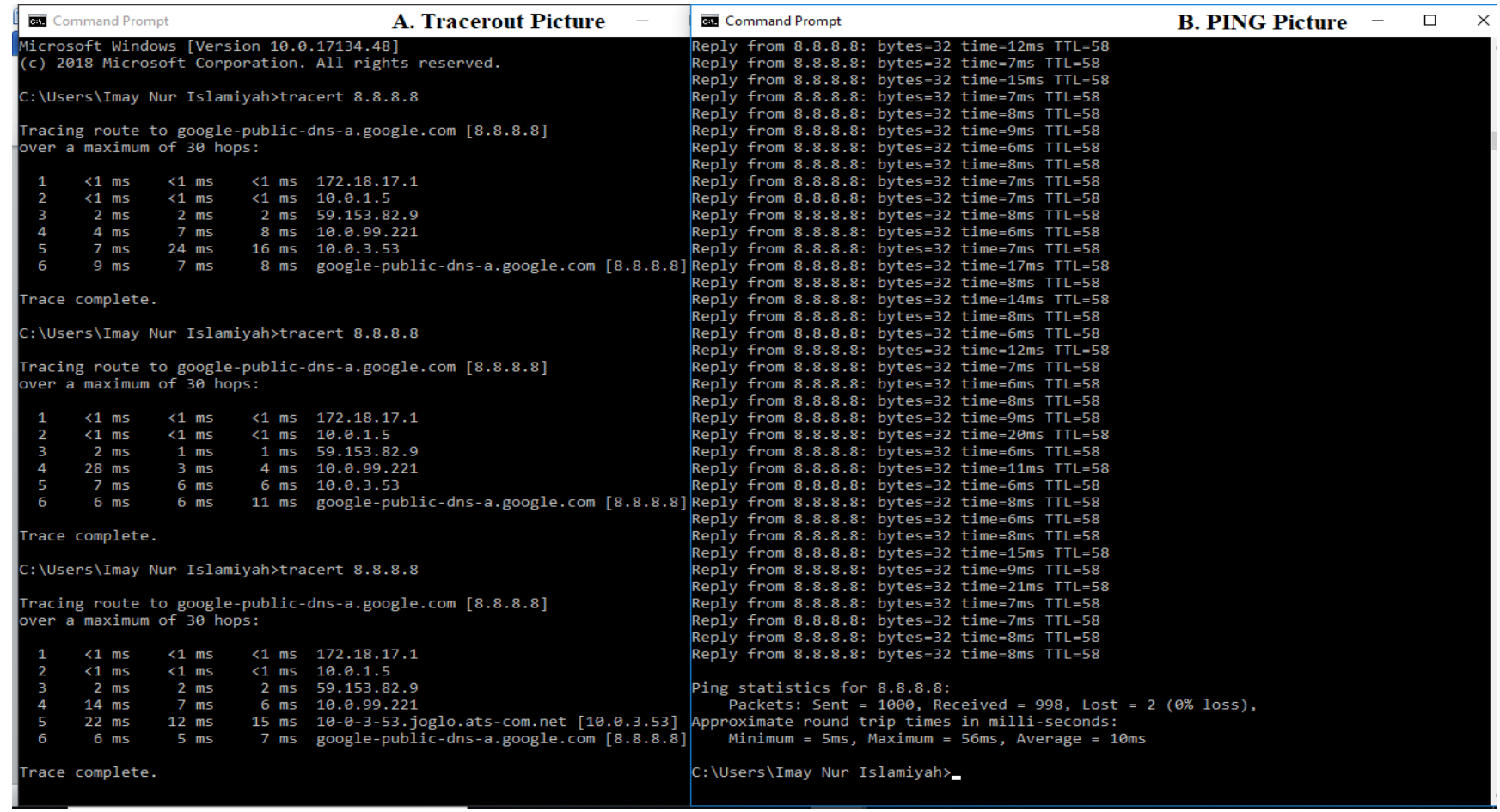

Fig 9: Ping and Traceroute VLAN Management

It can be seen from ping and traceroute in VLAN from PC5, the route directly pass-through to the Core-X. Both ping and traceroute get the shortest path. The data packet directly gets trough switch (layer 2). The average ping statistic from the experimental result as follows:

Ping statistics for 8.8.8.8:

Packets: Sent $=1000$, Received $=998$, Lost $=2(0 \%$ loss $)$,

Approximate round trip times in milli-seconds:

Minimum $=5 \mathrm{~ms}$, Maximum $=56 \mathrm{~ms}$, Average $=10 \mathrm{~ms}$

\subsection{OSPF Routing Design using VPLS over MPLS}

Figure 10 presents the network topology based on OSPF routing using VPLS over MPLS management. The IP configuration and routing path are the same as the previous scenario (routing OSPF on MPLS routing and VPLS). It connects PC5 to DHCP server using VPLS interface. PC5 get
IP automatically from Core-X.

Configuration on Core-X:

/mpls ldp

set enabled $=$ yes ls - -id $=10.0 .0 .1$ transport-address $=10.0 .0 .1$

/mpls ldp interface

add interface $=$ ether $2-$ CoreX-to-ROA1-2011

/interface vpls

add mac-address=02:E0:EA:5D:18:D4 name $=v p l s$-to-roal remote-peer $=10.0 .0 .2 \mathrm{vpls}$-id $=100: 0$

add mac-address=02:E0:EA:5D:18:D4 name $=v p l s$-to-rob1 remote-peer $=10.0 .0 .3 \mathrm{vpls}-\mathrm{id}=110: 0$

add mac-address=02:E0:EA:5D:18:D4 name=vpls-to-rodl remote-peer $=10.0 .0 .8 \mathrm{vpls}$-id $=120: 0$ 


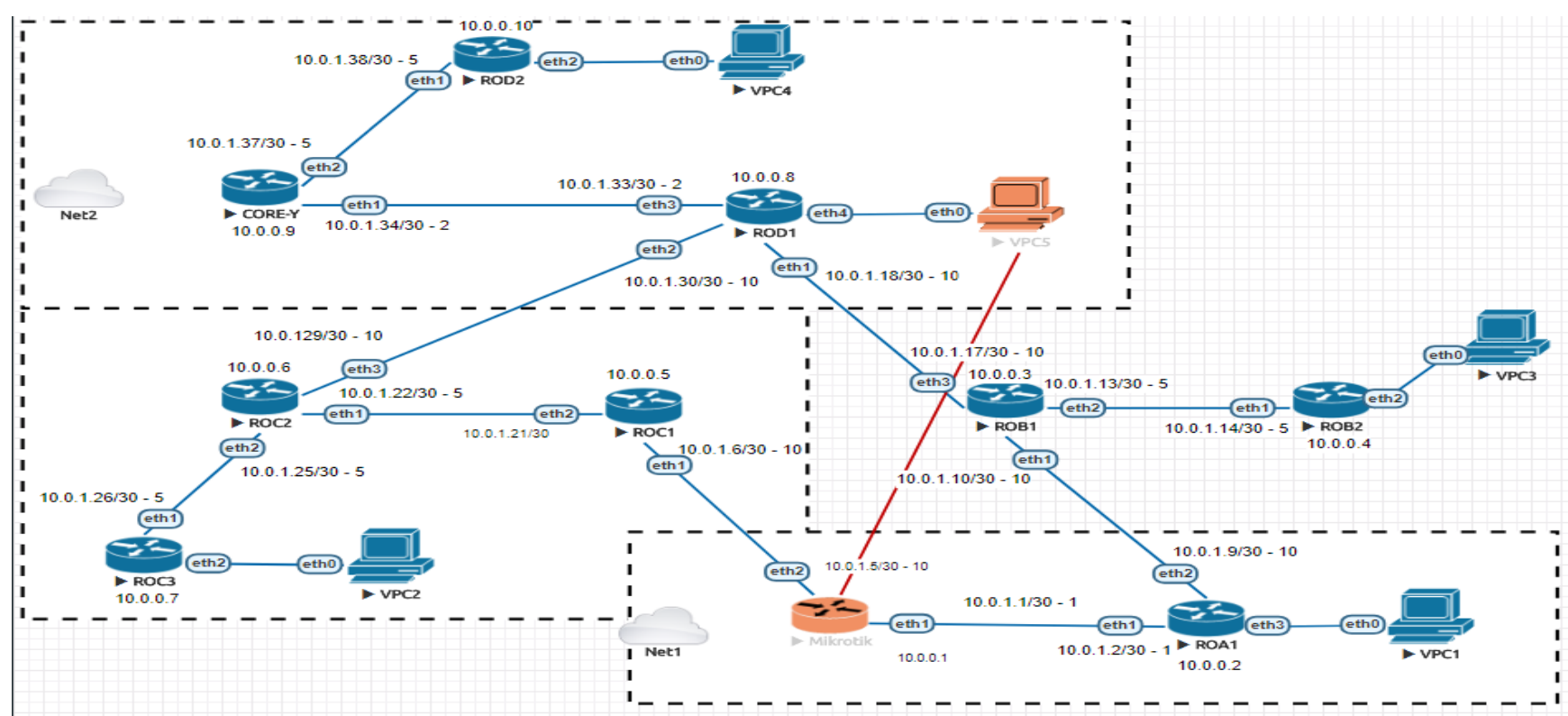

Fig 10: VPLS over MPLS on OSPF topology

/interface bridge port

add bridge $=$ bridge-lan interface $=v p l s-$ to - rod 1

Configuration on ROD1:

/mpls ldp

set enabled $=y e s l s r-i d=10.0 .0 .8$ transport-address $=10.0 .0 .8$

/mpls ldp interface

add interface $=$ ether $1-R O D 1-t o-R O B 1$

add interface $=$ ether2-ROD1-to-COREY /interface vpls

add mac-address=02:36:84:60:32:E2 name $=$ vpls-to-corex remote-peer $=10.0 .0 .1 \mathrm{vpls}$-id $=120: 0$

add mac-address=02:36:84:60:32:E2 name $=v p l s$-to-corey remote-peer $=10.0 .0 .9 \mathrm{vpls}$-id $=1000: 0$

add mac-address=02:36:84:60:32:E2 name $=v p l s$-to-rob1 remote-peer $=10.0 .0 .3 \mathrm{vpls}$-id $=140: 0$

The Result of ping and traceroute OSPF with VPLS management over MPLS in Fig. 11:

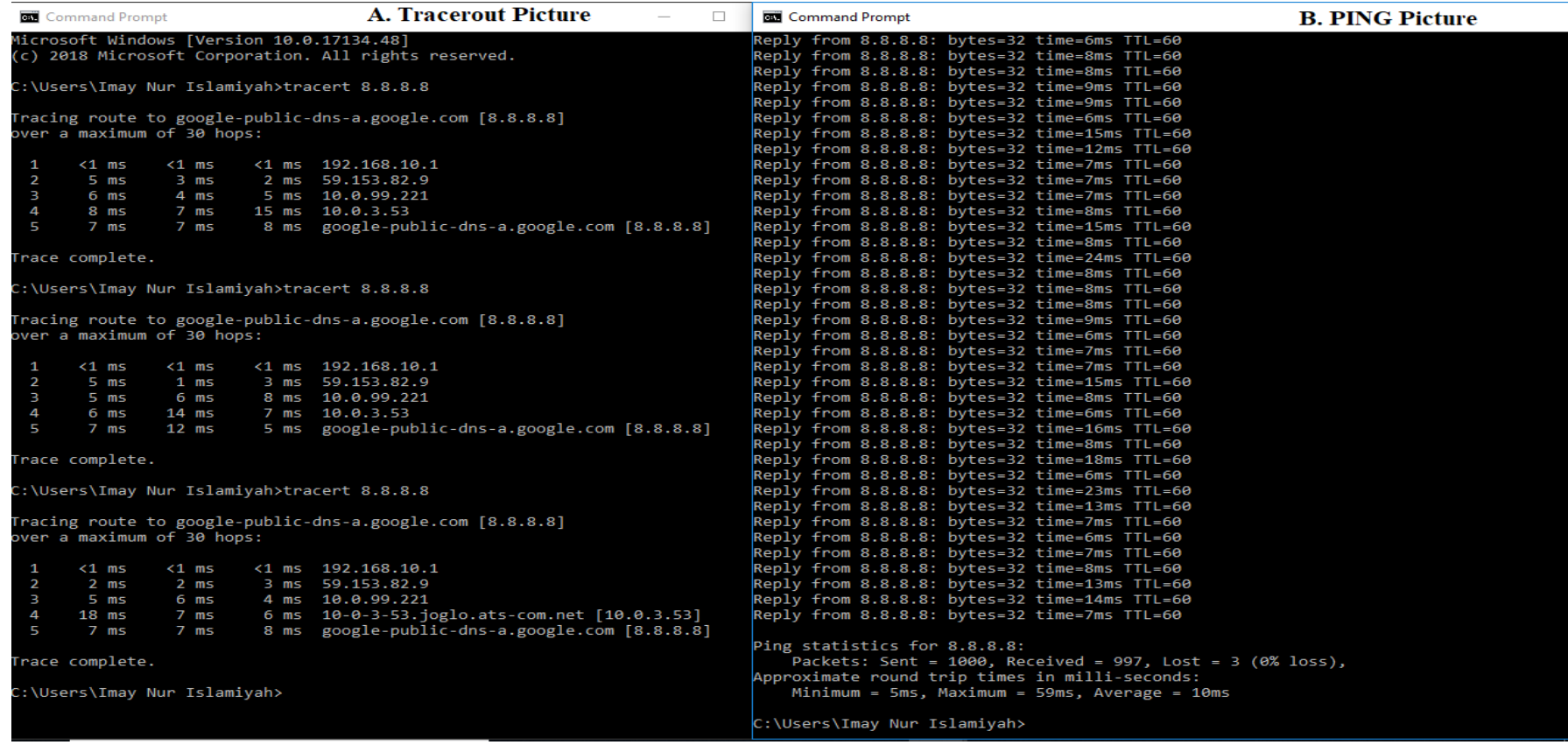

Fig 11: Ping and Traceroute VPLS over MPLS

The result of the ping and traceroute are shown in Figure 11. It can be seen that ping and traceroute on VPLS over MPLS are passed as well as on VLAN. There are a number of important differences between both configuration as follows:

Ping statistics for 8.8.8.8: 
Packets: Sent $=1000$, Received $=997$, Lost $=3(0 \%$ loss $)$,

Approximate round trip times in milli-seconds:

Minimum $=5 \mathrm{~ms}$, Maximum $=59 \mathrm{~ms}$, Average $=10 \mathrm{~ms}$

\section{Analysis of Quality Of Service (QoS)}

For the QoS analysis, the network packets are used namely UDP, TCP, and ICMP from the video conference. Ten times of measurement for QoS parameters, including connectivity, delay, jitter, and packet loss. The average measurement from each QoS parameter as a result.

\section{Delay}

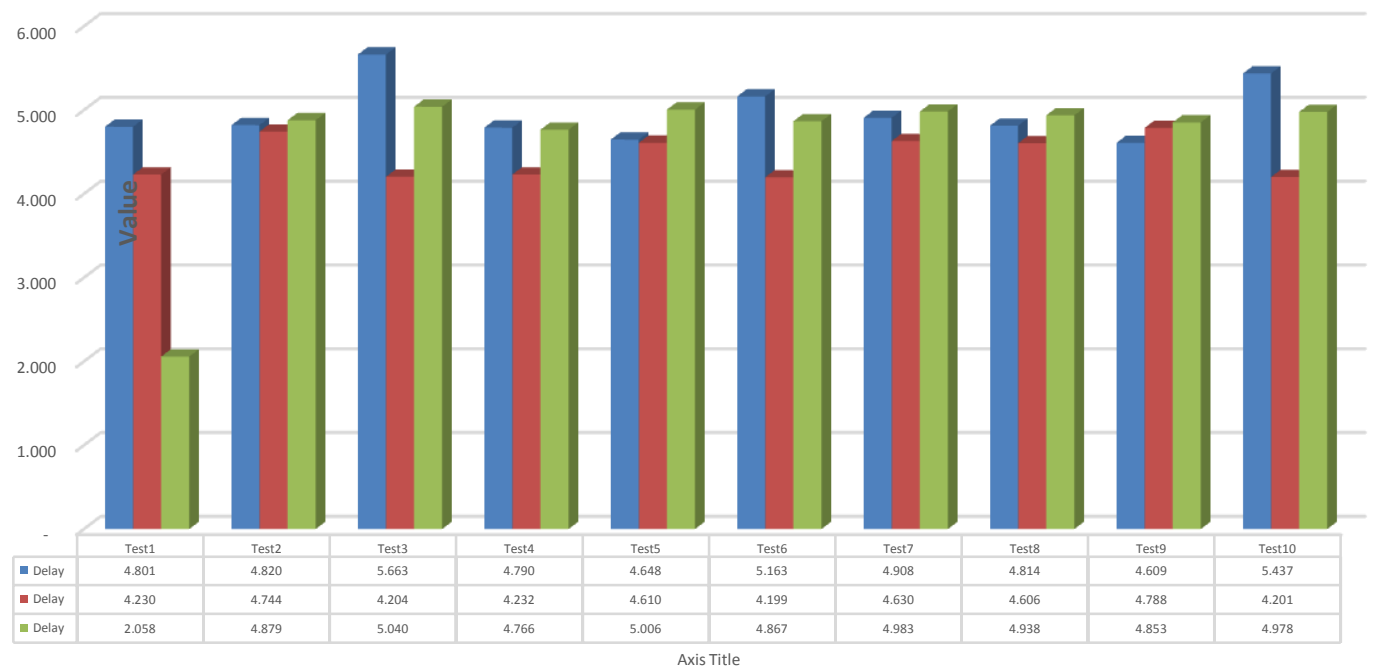

Jitter

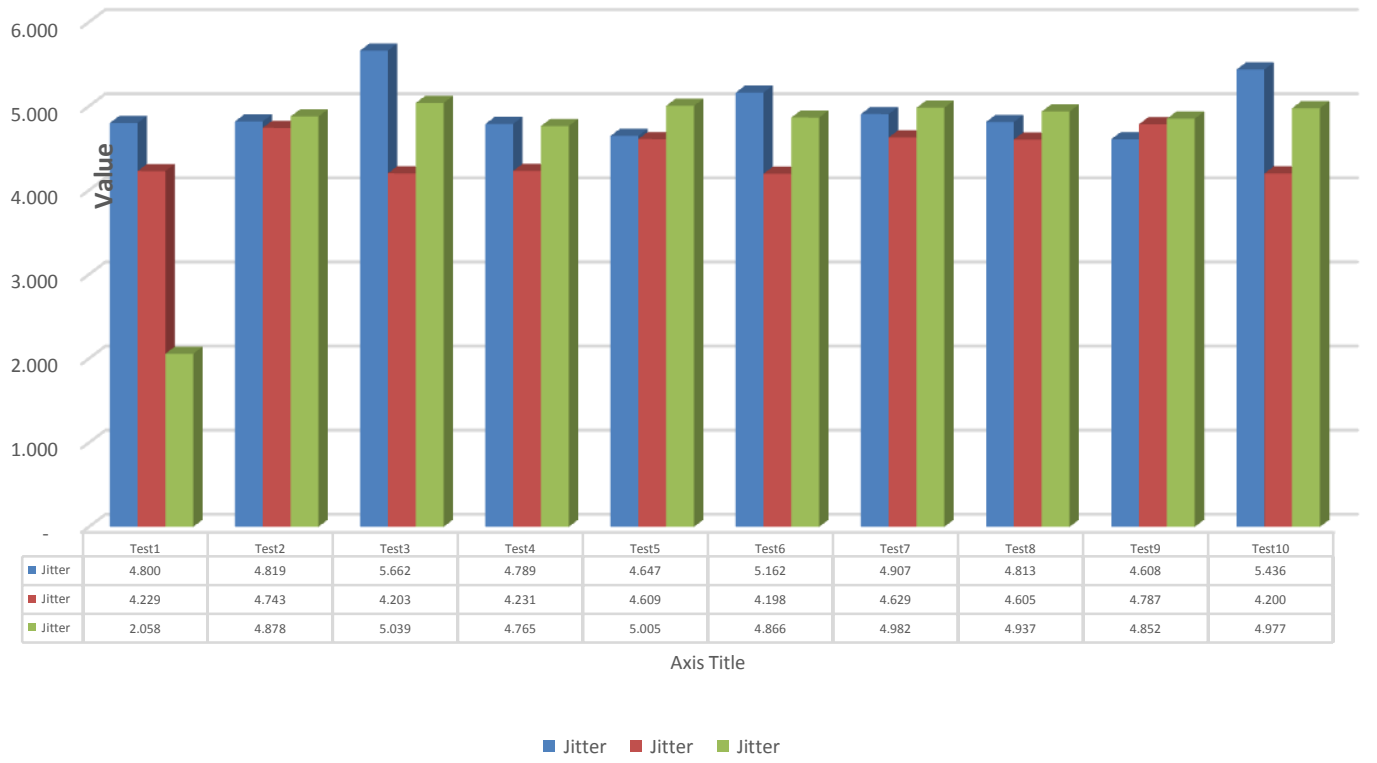



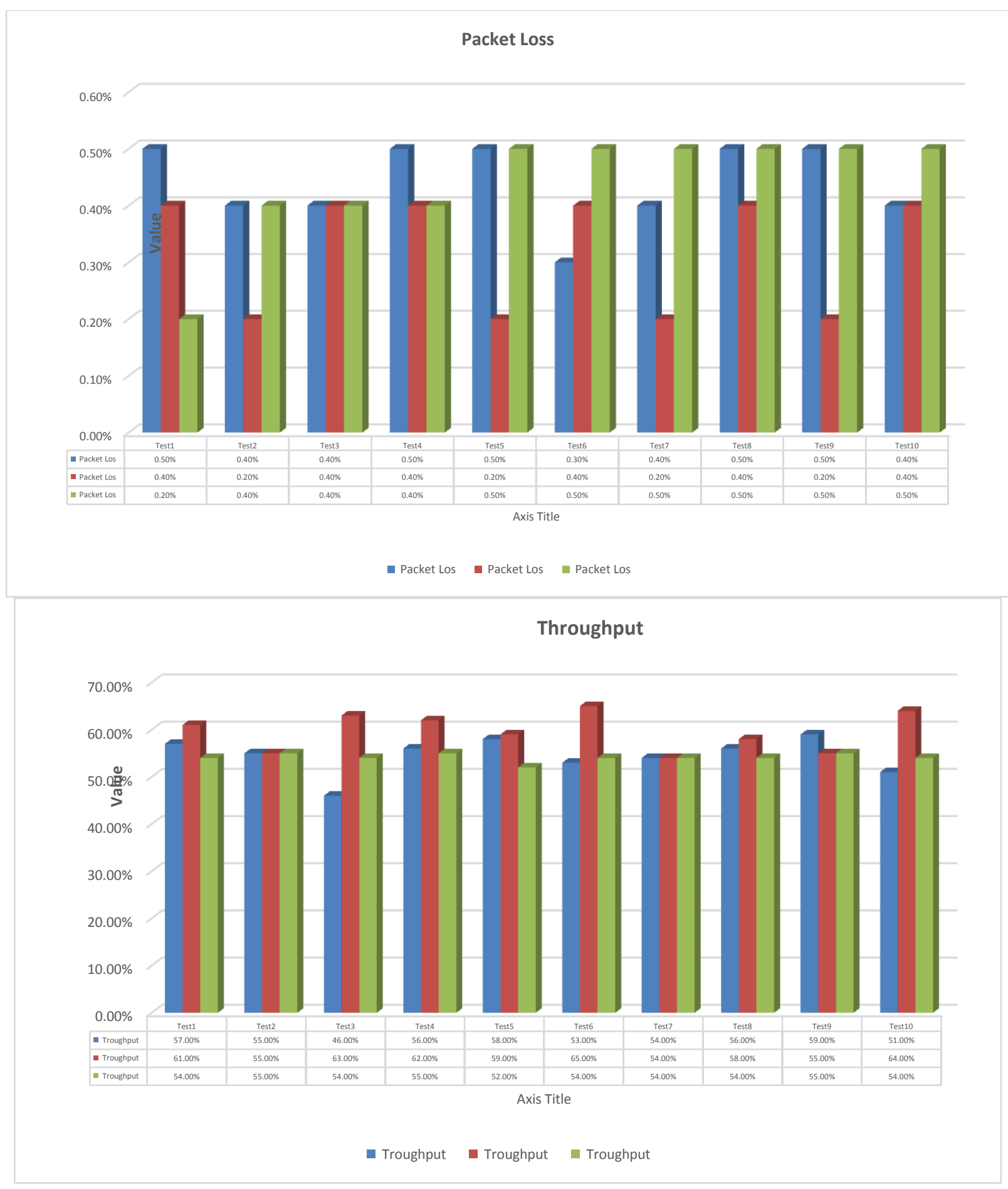

Fig 12: QoS Analysis

Figure 12 shows QoS measurement result for the delay, jitter, packet loss and throughput. The test was successful as it was able to get the average result of three networks in good condition (index value 3 ). However, network with the highest throughput is VLAN management, and the stable one is a network with the VPLS management over MPLS.

For the packet loss, the average results fall in the category "Very Good" (the index value 4). From the data in Figure 12, it is apparent that the packet loss in the network below $0.5 \%$. On the other hand, the delay has average results category "Good" in the index value 3. The results, as shown in Figure
12 , indicate that jitter measurement has a maximum amount of 5.437. The jitter measurement is similar to that delay.

The current study found that a stable network is VLAN management (see Table 7). In the infrastructure concept, VLAN is logically separate traffic in layer 2. Data packet traffic on a LAN has a tag that serves to identify the VLAN where the data packet is located. Then the switch forwards the packets to the corresponding ports in the VLAN. This situation can maintain the traffic of each VLAN as if they were in a separate physical infrastructure. However, data packets which transmitted at the same time still use the same 
trunk link and switch, and the corresponding output queue as well. Even though the data packages are arranged for different purposes and logically separated, the packages are still in the same queue.

Table 7. The average finding of $\mathrm{QoS}$ parameter in three scenario networks

\begin{tabular}{|c|c|c|c|c|}
\hline $\begin{array}{c}\text { QoS } \\
\text { Parameter }\end{array}$ & \multicolumn{3}{|c|}{ QoS Parameter Value } & $\begin{array}{c}\text { QoS } \\
\text { Category }\end{array}$ \\
\cline { 2 - 4 } & OSPF & $\begin{array}{c}\text { OSPF + } \\
\text { VLAN }\end{array}$ & $\begin{array}{c}\text { OSPF + } \\
\text { VPLS over } \\
\text { MPLS }\end{array}$ & \\
\hline Throughput & $54.5 \%$ & $59.6 \%$ & $54.1 \%$ & Good \\
\hline
\end{tabular}

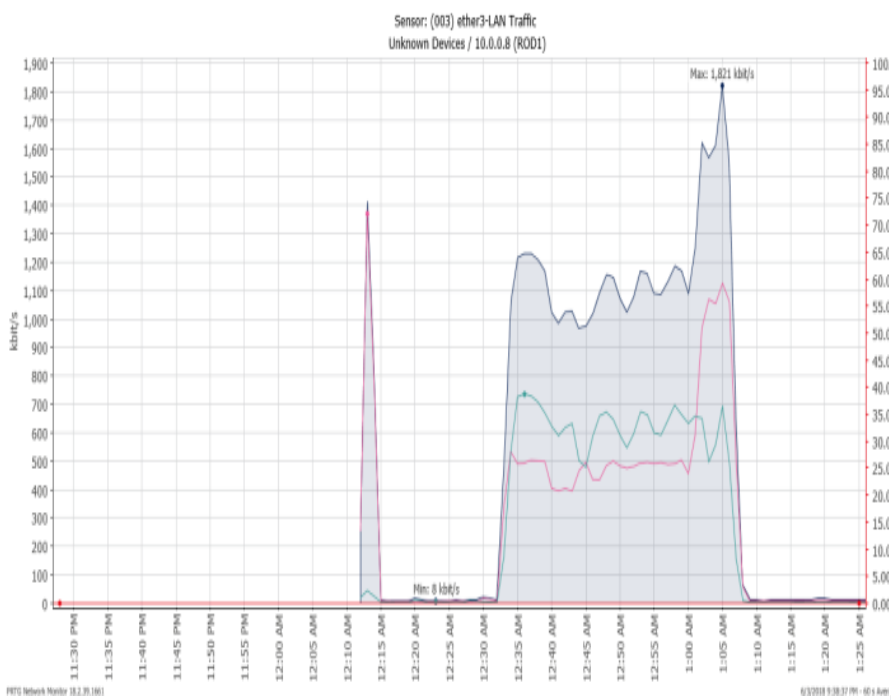

(a) Bandwidth on LAN interface for OSPF

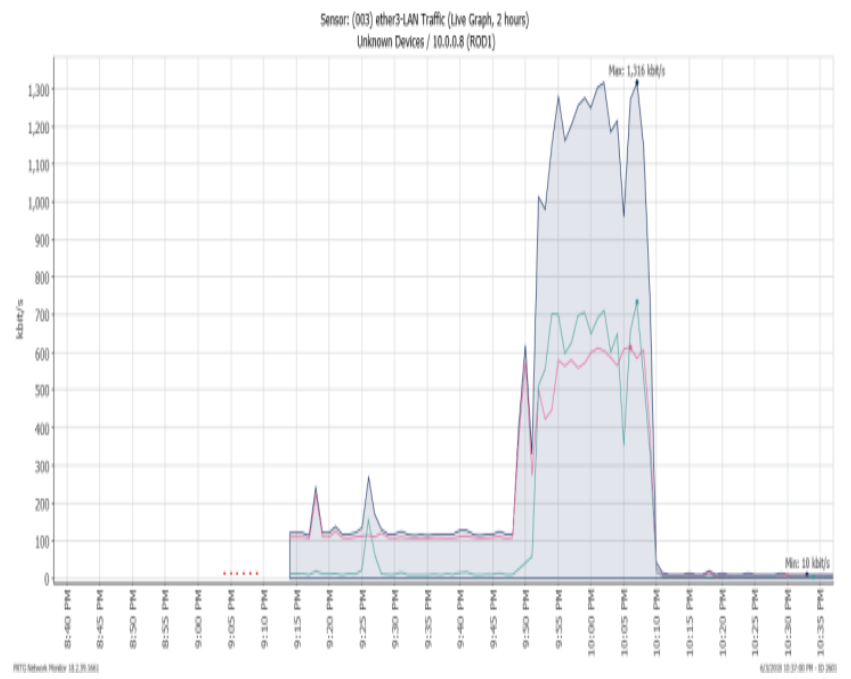

(c) Bandwidth on LAN interface for OSPF+VLAN Management

\begin{tabular}{|c|c|c|c|c|}
$\begin{array}{c}\text { Packet } \\
\text { Loss }\end{array}$ & $0.44 \%$ & $0.32 \%$ & $0.44 \%$ & $\begin{array}{c}\text { Very } \\
\text { Good }\end{array}$ \\
\hline Delay & $4.965 \mathrm{~ms}$ & $4.444 \mathrm{~ms}$ & $4.637 \mathrm{~ms}$ & Good \\
\hline Jitter & $4.964 \mathrm{~ms}$ & $4.443 \mathrm{~ms}$ & $4.6359 \mathrm{~ms}$ & Good \\
\hline
\end{tabular}

Furthermore, the Paessler Router Traffic Grapher (PRTG) is using to monitor network activity for the internet. PRTG is a software for monitoring resource network by SNMP. Illustrated for bandwidth traffic and CPU load can be seen in Fig. 13 and Fig 14.

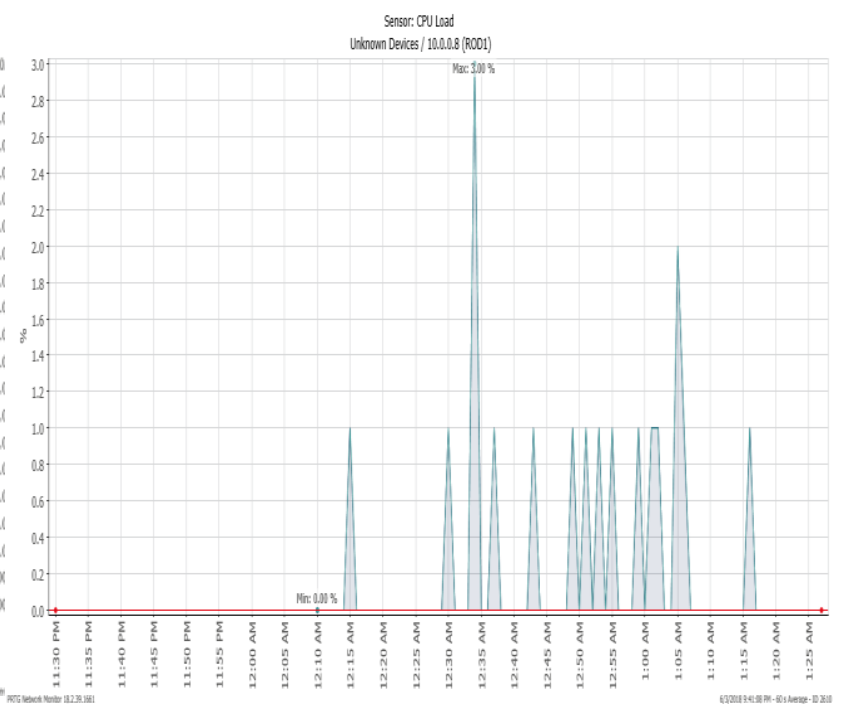

(b) CPU load for OSPF

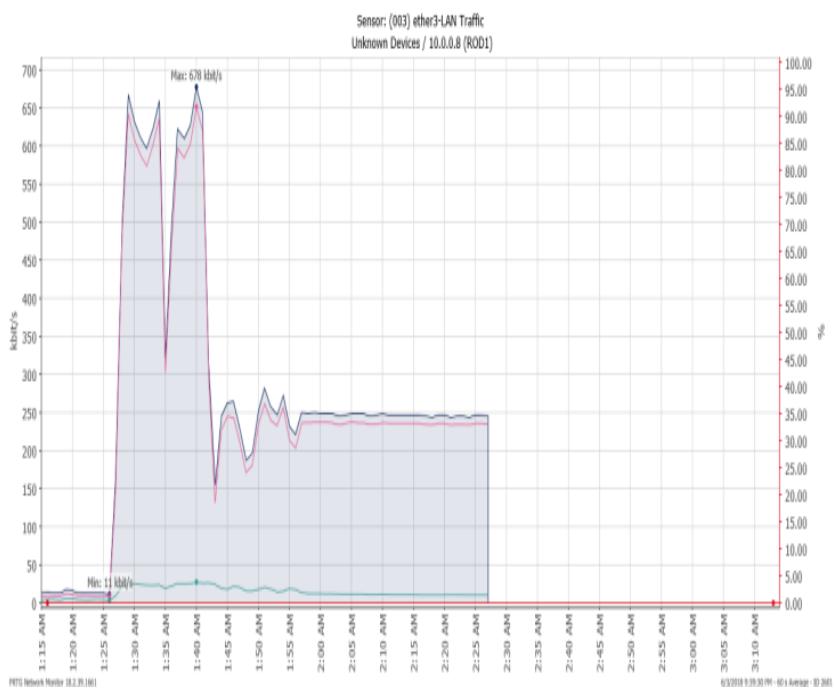

(d) CPU load for OSPF+VLAN Management

Fig 13: Bandwidth and CPU load using PRTG for OSPF routing and VLAN management 


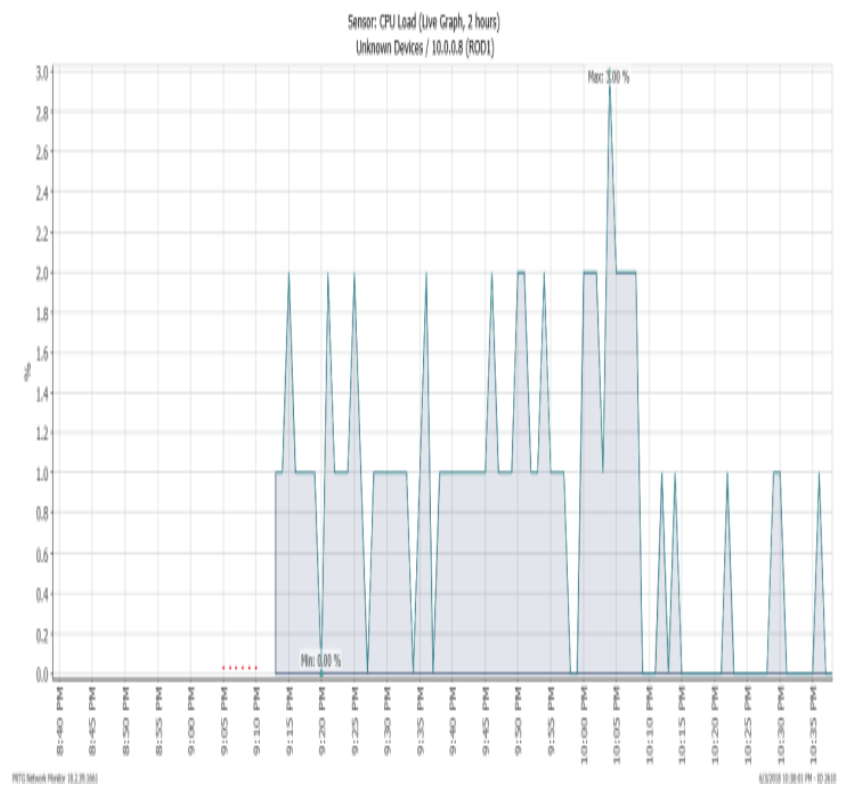

(a) Bandwith on LAN interface for OSPF+VPLS over MPLS

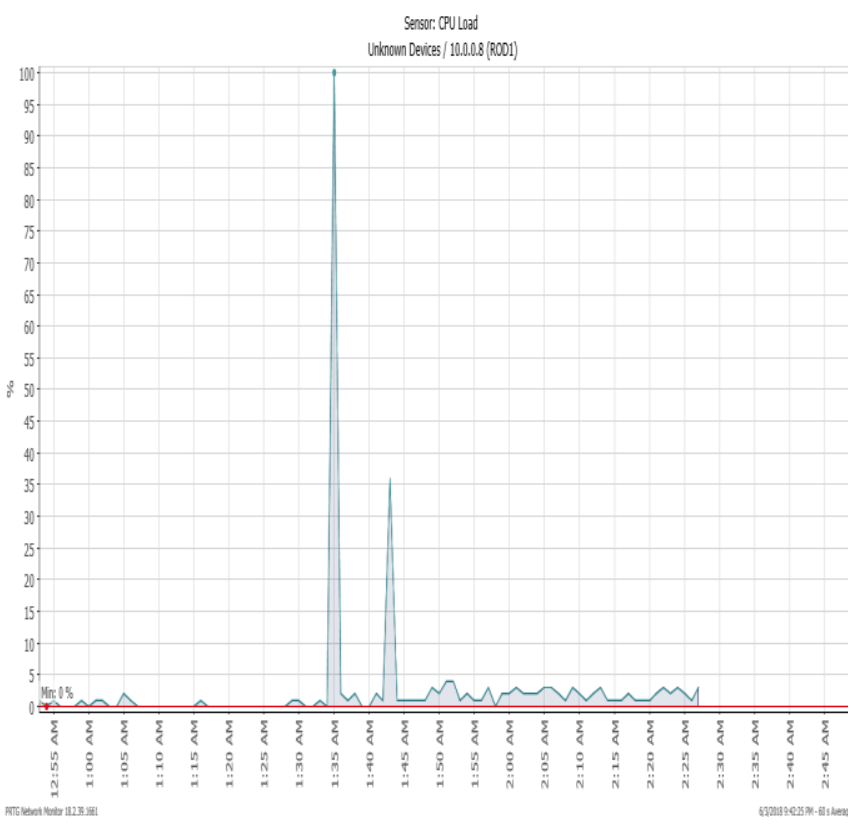

(b) CPU load for OSPF+VPLS over MPLS

\section{Fig 14: Bandwidth and CPU load using PRTG for VPLS over MPLS}

From the graph, Figure 13 can be seen that bandwidth and CPU load are observed for three kinds of network (OSPF, OSPF+VLAN management, and OSPF+VPLS over MPLS).

1. CPU load in OSPF has a maximum of $3 \%$. It means the router load is low.

2. CPU load in OSPF + VLAN management get a maximum of $3 \%$. For this condition, the router's capacity remains low.

3. CPU load in OSPF + VPLS over MPLS can reach $100 \%$. It means the performance of the router is very high.

\section{CONCLUSION}

This research was undertaken to design OSPF routing for IP internet network and evaluate their performance. Based on the experiment results, it can be concluded that VLAN Management and VPLS over MPLS can enhance video conference's performance. QoS parameters measurement, including packet loss, throughput, delay, and jitter, are categorised as "Good" based on TIPHON standard. The addition of VPN management and VPLS over MPLS scenario gives a significant effect. Implementation of VPN and VPLS over MPLS in video conference service can reduce packet loss, delay and jitter. VPLS over MPLS packet loss $0.44 \%$, delay $4.637 \mathrm{~ms}$ and jitter $4.636 \mathrm{~ms}$ respectively. Furthermore, the present study provides a comprehensive assessment of the VLAN management on OSPF, which has throughput value up to $59.6 \%$, packet loss up to $0.32 \%$, jitter and delay $4.44 \mathrm{~ms}$.

\section{REFERENCES}

[1] C. S. Parker, "Understanding Computers : Introductory." [Online]. Available: http://www.oakton.edu/user/2/rjtaylor/CIS101/Text/. [Accessed: 23-Mar-2018].

[2] APJII, "Penetration and behaviour of internet users." [Online]. Available: https://apjii.or.id/. [Accessed: 23Mar-2018].
[3] I. Nurhaida, D. Ramayanti, and R. Riesaputra, "DIGITAL SIGNATURE \& ENCRYPTION IMPLEMENTATION FOR INCREASING AUTHENTICATION, INTEGRITY, SECURITY AND DATA NON-REPUDIATION," Int. Res. J. Comput. Sci., vol. 4, no. 11, pp. 4-14, 2017.

[4] H. Kim and N. Feamster, "Improving Network Management with Software Defined Networking," IEEE Commun. Mag., no. February, pp. 114-119, 2013.

[5] Y. Chang, H. Tang, B. Li, and X. Yuan, "Distributed Joint Optimization Routing Algorithm Based on the Analytic Hierarchy Process for Wireless Sensor Networks," IEEE Commun. Lett., vol. 21, no. 12, pp. 2718-2721, 2017.

[6] L. Wang and A. K. M. M. Hoque, "OSPFN : An OSPF Based Routing Protocol for Named Data Networking," Named Data Networking, pp. 1-15, 2012.

[7] B. Rathi and E. F. Singh, "Performance Analysis of Distance Vector and Link State Routing Protocols," Int. J. Comput. Sci. Trends Technol., vol. 3, no. 4, pp. 23-32, 2015.

[8] A. Irmawati1, M. T. Indrarini Dyah Irawati, S.T., and M. T. Yuli Sun Hariyani, S.T., "IMPLEMENTATION OF OSPF ROUTING PROTOCOL FOR SOFTWARE DEFINED NETWORK BASE ON ROUTEFLOW," $e$ Proceeding Appl. Sci., vol. 3, no. Agustus, 2017.

[9] A. Wahab, F. A. Mustika, R. B. Bahawere, D. Setiawan, and M. Alaydrus, "Energy Efficiency and Loss of Transmission Data on Wireless Sensor Network with Obstacle," IEEE, 106AD.

[10] T. College, "Exploration and Practice for Virtual Local Area Network ( VLAN ) Technology Lianfeng Zhao," Appl. Mech. Mater., vol. 244, pp. 2299-2302, 2013.

[11] Cisco, "Cisco Series Switch." [Online]. Available: 
https://www.cisco.com/. [Accessed: 11-Mar-2018].

[12] D. A. J. Al-khaffaf, "Improving LAN Performance Based on IEEE802 . 1Q VLAN Switching Techniques," J. Univ. Babylon, no. 1, pp. 286-297, 2018.

[13] A. Iqbal, S. Benoit, and U. Dar, "Considerations in Designing DCI ( Data Centre Interconnect ) in Full Mesh VPLS / Multicast Enable WAN over OTV Tunnel," Int. J. Comput. Commun. Eng., vol. 6, no. 2, pp. 127-136, 2017.

[14] Mikrotik, "Documentation Manual TOC Mikrotik." [Online]. Available: https://wiki.mikrotik.com/wiki/Manual:TOC. [Accessed: 11-Mar-2018].

[15] T. Regula and M. A. Hussain, "Multi-level Structured Tree based Routing for Energy Efficiency in WSN," Int. J. Eng. Technol., vol. 7, pp. 5-9, 2018.

[16] F. Lu, J. Li, S. Jiang, Y. Song, and F. Wang, "Geographic Information and Node Selfish-Based Routing Algorithm for Delay Tolerant Networks," TSINGHUASCIENCEANDTECHNOLOGY, vol. 22, no. 3, pp. 243-253, 2017.

[17] S. Dehghan and A. M. Rahmani, "A new intelligent link state routing algorithm based on Credit Base-CMAC neural network," Int. Conf. Commun. Technol. Proceedings, ICCT, pp. 1109-1112, 2010.

[18] A. Felner, "Position Paper: Dijkstra' s Algorithm versus Uniform Cost Search or a Case Against Dijkstra' $s$ Algorithm," Symp. Comb. Search, pp. 47-51, 2011.

[19] Z. Yaojun, L. Hao, and R. Feng, "Applied Study of Layer 3 Switching Configuration Based on VLAN Among Colleges ' Library Network Systems," IEEE, 2011.

[20] L. Dian, D. Saputra, W. Sulistyo, U. Kristen, and S.
Wacana, "ANALISIS QOS DIFFERENTIATED SERVICE PADA JARINGAN MPLS," J. Teknol. Inf. dan Ilmu Komput., vol. 4, no. 4, pp. 227-236, 2017.

[21] A. U. B. Whiter and Jusak, "Implementasi VPLS pada Jaringan MPLS Berbasis Mikrotik," J. Control Netw. Syst., vol. 4, no. 2, pp. 1-8, 2015.

[22] D. A. I. Huijun, Q. U. Hua, and Z. Jihong, "QoS Routing Algorithm with Multi-Dimensions for Overlay Networks," China Commun., pp. 167-176, 2013.

[23] O. A. Umeh, K. A. Akpado, G. N. Okechukwu, and H. C. Ejiofor, "Throughput and Delay Analysis in a Real Time Network," Int. J. Eng. Appl. Sci., no. 12, pp. 27 34, 2015.

[24] A. Nindya, W. Wardhana, M. Yamin, and L. M. F. Aksara, "ANALISIS QUALITY of SERVICE (QoS) JARINGAN INTERNET BERBASIS WIRELESS LAN PADA LAYANAN INDIHOME," semanTIK, vol. 3, no. 2, pp. 49-58, 2017.

[25] A. R. Sudiyatmoko, S. N. Hertiana, and R. M. Negara, "Analisis Performansi Perutingan Link State Menggunakan Algoritma Djikstra Pada Platform Software Defined Network ( SDN )," J. Infotel, vol. 8, no. 1, pp. 40-46, 2016.

[26] J. W. Guck, A. Van Bemten, M. Reisslein, W. Kellerer, and S. Member, "Unicast QoS Routing Algorithms for SDN: A Comprehensive Survey and Performance Evaluation," IEEE Commun. Surv. TUTORIALS, vol. 20, no. 1, pp. 388-415, 2018.

[27] S. Budiyanto and A. S. Prasetyo, "STUDI ANALISIS PERFORMANSI PROTOKOL ROUTING IS-IS DAN OSPFv3 PADA IPv6 UNTUK LAYANAN VIDEO STREAMING," J. Teknol. Elektro, Univ. Mercu Buana, vol. 5, no. 1, pp. 18-32, 2014 